\title{
Prefrontal-Parietal Correlation during Performance of a Visuospatial Working Memory Task in Children, Adolescents and Young Adults
}

\author{
Miguel Angel Guevara, Jorge Carlos Hevia-Orozco, Araceli Sanz-Martin, \\ Lucía Ester Rizo-Martínez, Marisela Hernández-González, \\ Mayra Linné Almanza-Sepúlveda \\ Instituto de Neurociencias, CUCBA, Universidad de Guadalajara, Guadalajara, México \\ Email: aracelisanz@yahoo.com
}

Received 19 August 2015; accepted 26 September 2015; published 29 September 2015

Copyright (C) 2015 by authors and Scientific Research Publishing Inc.

This work is licensed under the Creative Commons Attribution International License (CC BY).

http://creativecommons.org/licenses/by/4.0/

c) (†) Open Access

\begin{abstract}
Development of the prefrontal cortex and its connectivity with different cortical areas has strong implications for the improvement of working memory. The aim of this research was to characterize the interhemispheric (INTER) prefrontal and hemispheric (INTRA) frontopolar-dorsolateral prefrontal and dorsolateral prefrontal-parietal correlation ( $r$ ) in children, adolescents and adults during performance of a visuospatial working memory task (VSWM). INTERr and INTRAr of 36 different aged male participants (11 - 13, 18 - 20 and $26-30$ years old) were calculated during performance of the Corsi Block-Tapping task, which assessed VSWM. On this task, children showed lower correct responses than adolescents and adults. Adults also showed lower total execution times than children and adolescents, with a more efficient performance. On the EEGs, the older groups showed both higher interfrontal correlations and left and right prefronto-parietal correlations than children. According to our results, the progressive efficiency in VSWM is related to differences in EEG patterns among children, adolescents and adults.
\end{abstract}

\section{Keywords}

Corsi Block-Tapping Task, EEG Correlations, Development, Visuospatial Working Memory

\section{Introduction}

Complex cognitive activities such as reasoning, language comprehension, planning, and spatial process are sus-

How to cite this paper: Guevara, M.A., et al. (2015) Prefrontal-Parietal Correlation during Performance of a Visuospatial Working Memory Task in Children, Adolescents and Young Adults. Journal of Behavioral and Brain Science, 5, 448-457. http://dx.doi.org/10.4236/jbbs.2015.510043 
tained by more basic functions, including working memory (WM) [1]. This is defined as interactive processes that involve temporal storage and manipulation of information which allow information to be held temporarily in an accessible state [2]. This kind of memory has been shown to improve with age [3], such that adolescents and adults can store more items than children [4] and process information more quickly, thus avoiding decay [5].

The Corsi Block-Tapping Test (CBTT) [6] has been widely used to assess visuospatial (VS) WM [7] in both healthy [8] and brain-damaged patients [9]. The task begins when the experimenter taps a sequence of touches on cubes placed on a board, which the participant then attempts to imitate either in the same order or backwards. The latter mode assesses WM because of the reordering to generate a new order of items [10].

According to Baddeley's model, the prefrontal cortex (PFC) provides the attention resources required to manipulate consciously short-term visuospatial or phonological information [11] in the right [9] and left hemispheres [12], respectively. For this reason, functional coupling between PFC and posterior cortical areas represents one of the most important neural bases of WM [13], the development of which may partially explain the improvement of WM capacity and some other high-order functions observed in adults [14].

Several studies of brain-damaged patients [9], including neuroimaging [15] [16] and electrophysiological approaches [17], have shown that the prefrontal cortex is functionally-coupled to parietal areas, and that the pattern activity of those areas shows clear development over time during performance of the VSWM task [18].

EEG is a useful tool to register electrical waves derived from the activity of pyramidal cells in the cortex [19]. One way to estimate the functional coupling between two different cortical areas is through electroencephalographic correlations (rEEG) [20], a mathematical index that makes it possible to determine the degree of similarity between two EEG signals during rest or cognitive task performance. This technique has been used to determine how such variables as sexual stimuli, alcohol, menstrual cycle, or age, affect functional coupling in the brain during performance of tasks that assess executive functions [21]-[23]. In relation to VSWM, EEG coherence, a feature of the EEG highly similar to the EEG correlation [24], has been used to assess the functional connectivity between prefrontal and parietal areas on WM tasks, where it has identified an increase in theta and alpha band correlations [17] [25] [26].

Considering these earlier findings, we designed a study with the objective of characterize interhemispheric (INTER) prefrontal and intrahemispheric (INTRA) frontopolar-dorsolateral prefrontal and dorsolateral prefrontal-parietal in children, adolescents and young adults during performance of the CBTT. We hypothesized that the INTER correlation would diminish during the task as age advanced, since hemispheric specialization and the prefronto-parietal correlation would increase during performance of the task, also in accordance with age.

\section{Method}

\subsection{Participants}

In this study participated 46 middle class Latino males, from which 10 were excluded because not reached a sufficient number of artifact-free EEG segments. The rest of the participants formed 3 groups: 12 children aged 11 to 13 years old (G1), 12 adolescents aged 18 to 20 years old (G2), and 12 young adults aged 26 to 30 years old (G3). Ages were selected in relation to the late maturation of the frontal lobes [27] and the executive functions [28]. Participants were enrolled in different elementary schools, campuses of the University of Guadalajara and postgraduate programs of metropolitan area of Guadalajara. Before make an appointment for the evaluation and EEG recordings, every potential participant was contacted via phone call to prove he met the inclusion criteria for this investigation.

Participants had the following characteristics: right-handed, no prior or current psychiatric or neurological disorders, no cognitive disabilities, IQ above 80 measured by WISC-IV [29] for G1or by WAIS-III [30] for G2 and G3, and normal scores on tasks that assess attention and memory using the NEUROPSI battery [31]. Subjects were invited to a single evaluation at the Institute of Neurosciences. None had performed the CBTT before this study. All procedures involved were approved by the Ethics Committee of the Institute of Neuroscience in accordance with the ethical standards laid down in the 1964 Helsinki Declaration, and all participants gave their informed consent prior to their inclusion. This study was conducted from August to December 2012.

\subsection{Corsi Block-Tapping Task}

A computerized version of the CBTT (CubmemPC.exe) was used [8], in which 10 blue cubes are shown on a 
computer screen against a rectangular gray background. The task begins when the participant touches the computer screen (touch screen) to initiate automatically a sequence of cubes. To emulate the sequence of cubes that the examiner taps, the program changes the color of the cubes that are tapped from blue to yellow (1-second duration), one-by-one and sequentially to form a series of bins, whose length increases progressively up to a series of 7 cubes (4 trials for each length). Immediately after the last cube of the sequence had been light, participant had to reproduce the sequence presented before in the backward order by touching the cubes on the screen. The total number of trials was 24 , and the following parameters were measured: onset latency (OL), total execution time (TET), correct trials (CT), and the longest sequence or span.

\subsection{EEG Procedure}

EEG signals were recorded in a shielded, dimly-lit room, with subjects seated in a comfortable position approximately $50 \mathrm{~cm}$ away from the screen, in two conditions: with eyes open at rest (3 minutes), and during performance of the Corsi task (7 minutes maximum), with a 3-min interval between recordings. EEG recordings were taken at six derivations of the International 10/20 System [32]: F1, F2 [bilateral frontopolar, BA 10], F3, F4 [dorsolateral prefrontal cortex, DLPFC, BA 46] [33], and P3, P4 [parietal areas, BA 7] [34]. All derivations were referred to linked ears with the ground electrode placed on the forehead. EEGs were amplified using a Grass model P7 polygraph with EEG filters set at 1 and 50Hz. Impedance for the EEG electrodes was kept below $10 \mathrm{kV}$. CAPTUSEN software [35] was used to perform sampling (1024 points at a sample rate of $512 \mathrm{~Hz}$ ) and store the EEG data for off-line processing. In addition, electroculogram were recorded to detect eye-movement artifacts using a bipolar montage with electrodes placed at the outer canthi of both eyes. Epoch rejection was based on both visual and computer selection. Thus, the EEG epochs that were visually identified as contaminated by noise were removed manually using a computer program (CHECASEN) [36].

The recordings were then reduced to 40 epochs (approx. $2 \mathrm{~s}$ each), which were representative of the entire time of EEG recording. EEGs were analyzed by the EEGMAGIC computer program [37], which initially calculated the Fast Fourier Transform (FFT) to six frequency bands: delta $(1.5$ - $3.5 \mathrm{~Hz})$, theta $(3.5$ - $7.5 \mathrm{~Hz})$, alpha-1 (7.5 - 10.5 Hz), alpha-2 (10.5 - 13.5 Hz), beta-1 $(13.5$ - $19.5 \mathrm{~Hz})$, beta-2 $(19.5-30 \mathrm{~Hz})$ and gamma $(31-50 \mathrm{~Hz})$. The correlation spectrum is then calculated from the autospectra and the cross-spectrum of the signals' proportioning values between -1 and +1 . Correlation spectra at 0 delay for each subject and condition were obtained for each frequency band using amplitude values by means of Pearson product-moment coefficients to obtain interhemispheric correlations (INTERr) between homologous left and right derivations (F1-F2; F3-F4) and intrahemispheric correlations (INTRAr) between derivations in the same hemisphere (F1-F3, F3-P3 and F2-F4, F4-P4 in the left and right hemispheres, respectively). Correlation values were transformed to Fisher's z-scores to approximate them to a normal distribution before conducting the statistical procedure. Z-score calculations were based on individual scores.

\subsection{Statistical Analyses}

To compare performance on the Corsi task and the EEG correlations among age groups we used one-factor ANOVAs for each behavioral parameter (reaction time, span, total execution time, correct trials), as well as the EEGs for each pair of derivations (F1-F2, F3-F4, F1-F3, F2-F4, F3-P3, F4-P4) in each band. A Tukey test was then performed at a significance level of 0.05. Only the EEGs recorded during the Corsi Task were analyzed.

In addition, to determine how EEG activity is related to performance of the Corsi task, a Pearson correlation was performed between the different parameters of EEG activity during the task and the behavioral scores from the task, as in previous studies [23] [38].

\section{Results}

\subsection{Behavioral Performance}

There were no significant differences between groups in onset latency. On both span $\left(\mathrm{F}_{2,33}=13.07, \mathrm{p} \leq 0.0001\right.$, $\eta=0.442)$ and correct trials $\left(\mathrm{F}_{2,33}=13.92, \mathrm{p} \leq 0.0000, \eta=0.458\right)$, G2 and G3 retained more items than G1 (Figure 1). With respect to total execution time, only G3 had a shorter runtime (in seconds) than $G 1\left(F_{2,33}=5.13\right.$, $p$ $\leq 0.01, \eta=0.237)$; $\mathrm{G} 3$ was faster than $\mathrm{G} 2$ but this difference was not statistically significant $(\mathrm{p} \leq 0.09)$ (Figure 1 ). 


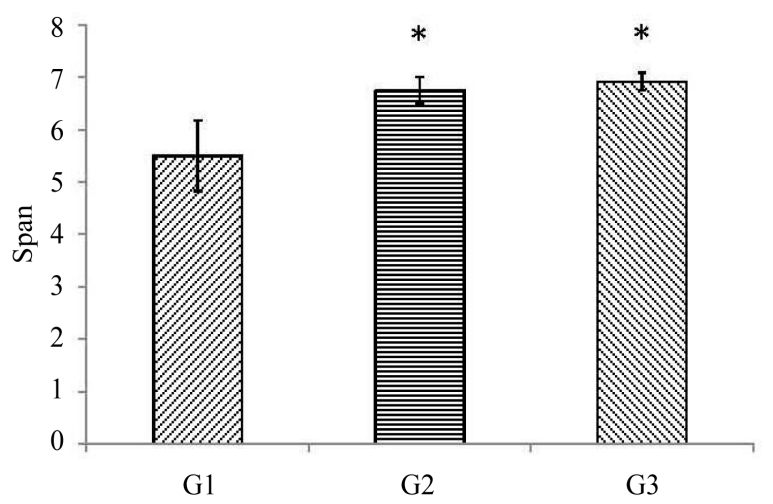

(a)

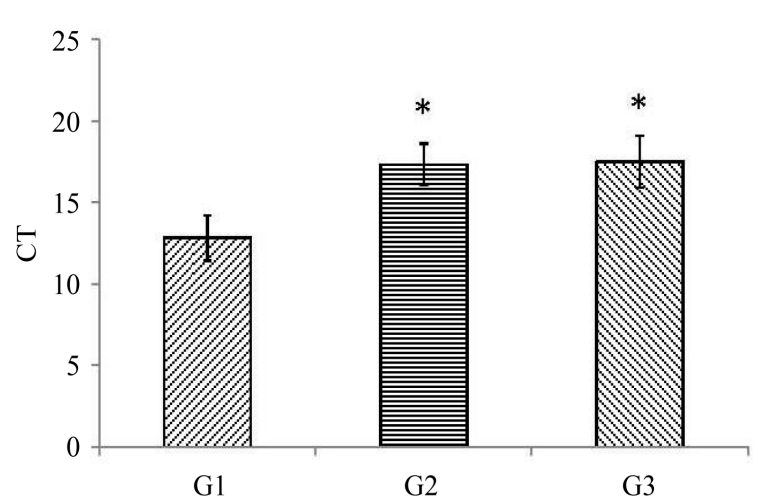

(b)

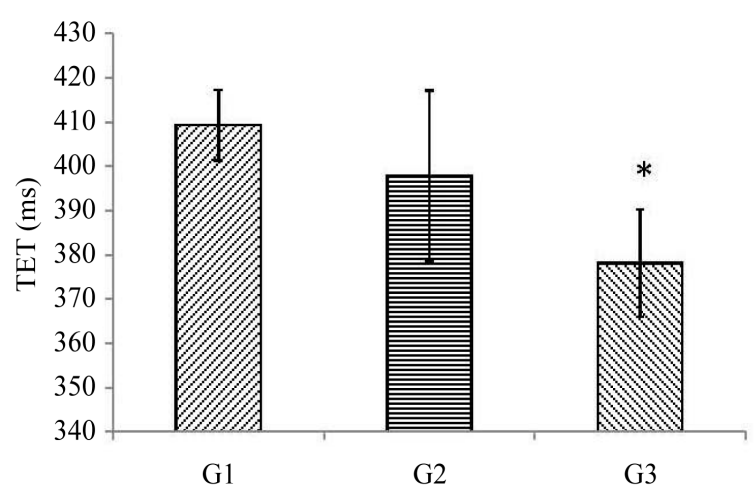

(c)

Figure 1. Mean ( \pm 2 S.D.) of performance scores in CBTT. Significant differences among groups area indicated with *p $\leq$ 0.0001 or $+\leq 0.01$. (a) Span, G2 and G3, regarding G1; (b) Correct trials (CT), G2 and G3, regarding G1; (c) Total execution time (TET) from G2 and G3, regarding G1.

\section{2. rEEG Data}

1) Inter-hemispheric correlation

For the bilateral INTERr DLPFC (F3-F4) during task execution, a higher correlation occurred in alpha-2 $\left(\mathrm{F}_{2,33}\right.$ $=5.83, \mathrm{p} \leq 0.006, \eta=0.261)$, beta- $1\left(\mathrm{~F}_{2,33}=5.36, \mathrm{p} \leq 0.009, \eta=0.245\right)$ and beta-2 $\left(\mathrm{F}_{2,33}=7.23, \mathrm{p} \leq 0.002, \eta=\right.$ 0.305 ) in G2 and G3 compared to G1 (Figure 2).

2) Intra-hemispheric correlation

For the right INTRAr frontopolar-DLPFC (F2-F4), the study found a higher correlation in alpha-2 $\left(\mathrm{F}_{2,33}=\right.$ $3.60, \mathrm{p} \leq 0.037, \eta=0.179$ ) in G2 compared to G1 (Figure 3(a)), while for the right INTRAr DLPFC-parietal (F4-P4) during task execution it found a higher correlation in $\mathrm{G} 2$ in beta-2 $\left(\mathrm{F}_{2,33}=4.57, \mathrm{p} \leq 0.017, \eta=0.217\right)$ compared to G1 (Figure 3(b)). Finally, for the left INTRAr DLPFC-parietal (F3-P3) during task execution it found a higher correlation in G3 in beta- $1\left(\mathrm{~F}_{2,33}=4.71, \mathrm{p} \leq 0.015, \eta=0.222\right)$ compared to $\mathrm{G} 1$ and in beta-2 in $\mathrm{G} 2\left(\mathrm{~F}_{2,33}=3.97, \mathrm{p} \leq 0.027, \eta=0.194\right)$ compared to G1 (Figure 3(c)).

\subsection{Correlation between Behavioral and rEEG Results}

A positive correlation was found between the parameter total number of correct trials and: the F2-F4 alpha-2 ( $\mathrm{r}$ $=0.465, \mathrm{p}=0.004)$ (Figure 4(a)), the F4-P4 beta-2 $(\mathrm{r}=0.334, \mathrm{p}=0.047)$ (Figure 4(b)), and the F3-F4 beta-2 band $(r=0.400, p \leq 0.016)$ (Figure $4(c))$ when the three groups were mixed.

\section{Discussion}

This study found differences among three age groups for both the behavioral and EEG-recording parameters. In terms of behavior, G2 and G3 had more correct responses than G1, but G3 showed a faster execution time. In 


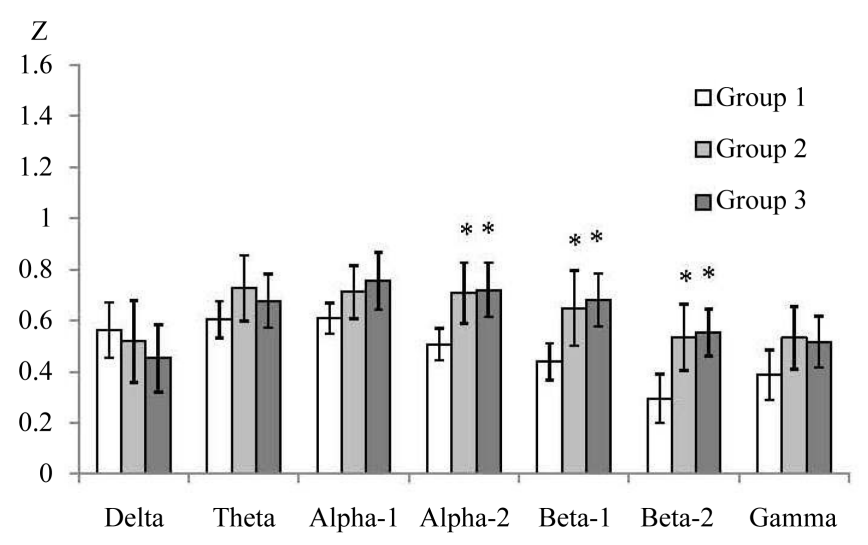

Figure 2. Mean ( \pm 2 S.D.) of the DLPFC INTERr (F3-F4) in all bands in G1, G2 and G3. The significant differences between older groups $(\mathrm{G} 2, \mathrm{G} 3)$ and $\mathrm{G} 1$ are shown with *p $\leq 0.05$.

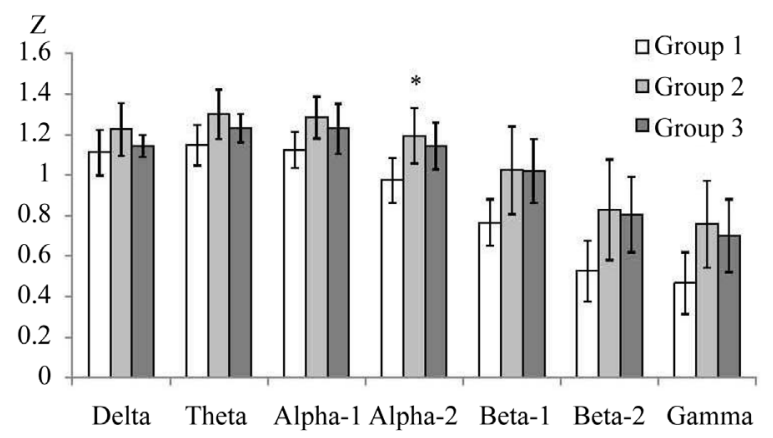

(a)

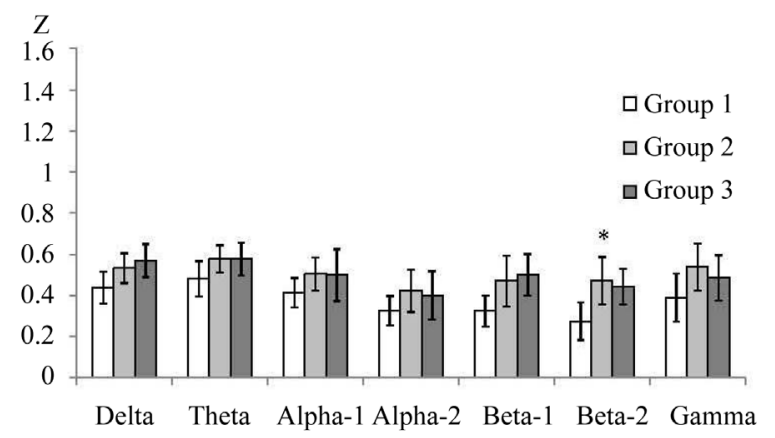

(b)

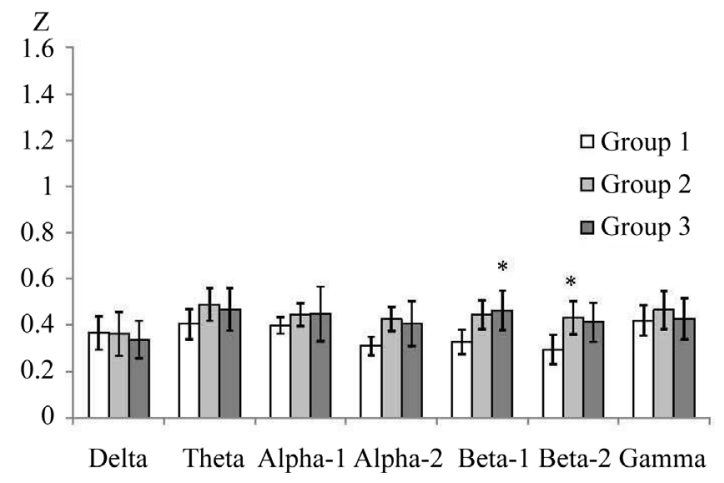

(c)

Figure 3. Mean ( \pm 2 S.D.) of the INTRAr correlation in derivations and bands where there were significant differences among groups, $* p \leq 0.05$. (a) right frontopolar-DLPFC, significant differences in G2 in comparison with G1; (b) right DLPFC-parietal, significant differences in G2 in comparison with G1; (c) left DLPFC-parietal, significant differences in G2 and G3 in comparison with G1.

the EEG results, the main differences were found in the intra-hemispheric prefronto-parietal correlation. In contrast to our hypothesis, functional coupling did not increase in accordance with age; a finding is discussed in the following section.

1) Behavioral performance

As mentioned above, older groups were able to maintain more items in working memory than children, thus confirming the results reported in other studies [7] [39] [40]. This indicates that the capacity to manipulate and retain items improves with age. 


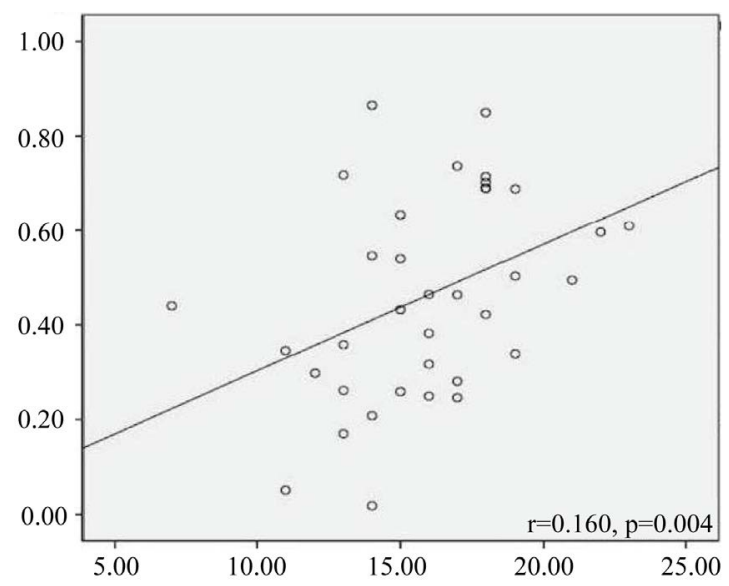

(a)

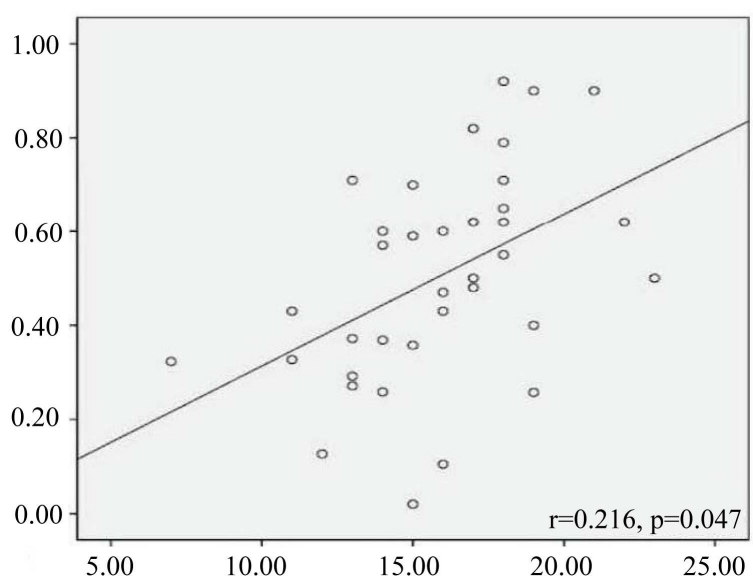

(b)

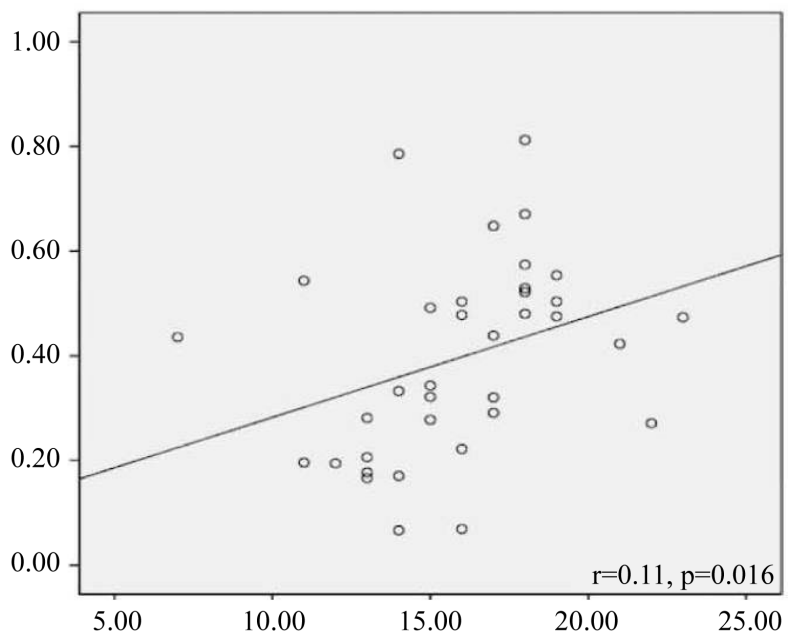

(c)

Figure 4. Scatterplots between Correct trials in the Corsi Block Taping Test (x axis) and EEG correlation (y axis) in: (a) F3-F4, beta-2 band; (b) F2-F4, alpha-2 band; (c) F4-P4, beta-2 band.

Although G2 and G3 had better performance than G1, when total execution times were compared, only the participants in G3 presented a faster time than G1. The combination of higher performance with lower time could suggest that the VWM of G3 is more efficient than that of G2 and G1. In this sense, efficiency is defined as the ability to perform, or produce, something without wasting materials, time or energy [41], an idea that will be discussed in greater detail below in the analysis of the EEG correlations.

With respect to total execution time, studies have described an increase in processing information speed with age [42], and argued that this rate is a factor that maintains the efficacy of execution on working memory tasks and prevents decay of internal representations of the environment [43]. The processing speed shown at the end of the second decade of life may be based on the complete cell myelination that is observed from 20 to 29 years of age [28], and which increases the speed of conduction of nerve impulses that may be related to better performance on cognitive tasks [44]. However, additional studies are needed to detect whether such changes are driven by reduced control inhibition or by greater processing speed.

2) rEEG

We found a higher DLPFC-INTERr in G2 and G3 compared to G1, a fact that could explain the higher VSWM capacity. In this sense, many previous works have demonstrated that both high memory load [45] [46] and the complexity of the cognitive task [47] demand the bilateral participation of both hemispheres, specifically in the DLPFC. This is particularly true when the demand for information maintenance exceeds the capacity of the slave systems, as could happen in older groups [48]. In contrast, children could activate other cortical areas 
to load memory, probably occipital ones, as previous works have reported [18]. This could indicate that neural processing in children is different from that of young adults and adolescents, and is clearly less efficient, according to our behavioral results.

In addition, the bands that showed a higher DLPFC-INTERr in G2 and G3 were alpha-2, beta-1 and beta-2. The higher alpha correlation could be a consequence of surpassing the capacity limits on a short-term memory task, as in the longer sequences in our study [49]. The presence of the beta-1 band, meanwhile, could reflect the mental process required to hold the object representation for the short memory [50] needed in this case to achieve better execution. In our study, the evocation of items in backward order involved manipulating information so that as sequence length increased, the task became more cognitively demanding [51]. A limitation of the present study was we did not compare EEG recordings in different span, so, we were not able to determine the changes in the functional interhemispheric coupling during different memory load.

With respect to the right frontopolar-DLPFC and DLPFC-parietal correlation, G2 had a higher INTRAr than G1 in the alpha-2 and beta-2 bands. This result is congruent with previous neuroimaging studies which have found that right prefrontal and parietal activation show a linear increase from childhood to adolescence during a VSWM task [27] [52], although this finding based on samples of age groups from childhood to the early twenties (22 years old).

In contrast, our study included older participants. However, similar to our results, other neuroimaging studies have found higher activity in the DLPFC and parietal areas in adolescents compared to children and young adults on VSWM tasks [53] and various executive function tasks [54]. Considering this, it is possible that the difference in functional coupling between G2 and G1 could indicate that adolescents have a more general and non-specific neural activity [55] that requires the integration of more association areas, such as the parietal regions. It is probable that adolescents have not completed synaptic pruning in the DLPFC and parietal regions [56] [57]; thus the transition from adolescence to adulthood involves even greater neural specialization for information processing in the VSWM. As Scherf et al. [53] observed changes in VSWM execution from childhood to adolescence were marked by quantitative changes, while those from adolescence to adult-like performance were marked by qualitative ones.

When analyzing the differences in bands between G2 and G1, many studies have suggested that alpha is strongly related to semantic coding [49], whereas beta has been associated with task performance, since it remains high over a time delay and decays with the subject's performance, which is functionally related to both maintenance of mental representations during short-term memory tasks and motor preparation [50].

Our study found that the left DLPFC-parietal correlation was higher in G3 than G1 in the beta bands. Other studies also found a functional involvement of the left hemisphere [56] on VSWM tasks. Indeed, left hemispheric involvement has been identified in long-sequence verbal tasks [18] and may underlie processes of subvocal rehearsal in the working memory [58]. It may be that visuospatial processing is facilitated by sub-vocal skills that are strengthened as an adult-level strategy developed to improve VSWM functions. This possibility was also explored in the results of a study that found higher left fronto-parietal beta- 1 coherence in sentences that involved greater verbal working memory demands, since more difficulty in understanding was seen in age groups quite similar to the ones tested in our work [59]. Besides, the lower left DLPFC-parietal correlation in beta-2 in G1 could be related to deficits in communication among different cortical association areas [60], and therefore, with poorer performance on VSWM tasks.

The significant correlation between total number of correct trials and EEG correlation confirmed the participation of frontopolar-DLPFC and DLPFC-parietal circuits in spatial working memory tasks [9] [15] [17]. The bands alpha-2 and beta-2, that showed a significant correlation with behavioral parameters, are implicated in classic working memory tasks [61]. Our results suggest that these bands could be considered as effective predictors of a working memory capacity.

Finally, we consider that in future studies it will be important to compare EEG correlations on tasks with sequences of differing lengths in order to analyze progressive hemispheric functional coupling. In addition, to determine the way in which the left hemisphere participates in VSWM tasks, it would be useful to include a verbal interference to explore whether sub-vocal rehearsal participates in such tasks.

\section{Conclusion}

In this study, we observed that young and late adolescents had a higher performance than children on the CBTT, 
but that young adults performed the task more efficiently. These behavioral results are related to a characteristic rEEG pattern marked by a higher DLPFC correlation in both adults and adolescents, and a higher functional coupling between the right prefrontal and parietal areas only in adolescents. Also, adults show a left-lateralized functional coupling between the DLPFC and parietal areas, which probably reflects the use of sub-vocal rehearsal. Finally, the relation of the alpha and beta bands to the efficacy of task performance suggests a continuity of this EEG activity only in VSWM capacity development, though additional studies are needed to confirm this assumption.

\section{References}

[1] Baddeley, A. (1996) The Fractionation of Working Memory. Proceedings of the National Academy of Sciences of the United States of America, 93, 13468-13472. http://dx.doi.org/10.1073/pnas.93.24.13468

[2] Cowan, N. (1998) Visual and Auditory Working Memory Capacity. Trends in Cognitive Sciences, 2, 77. http://dx.doi.org/10.1016/S1364-6613(98)01144-9

[3] Matute, E., Sanz, A., Gumá, E., Roselli, M. and Ardila, A. (2009) Influencia del nivel educativo de los padres, el tipo de escuela y el sexo en el desarrollo de la atención y la memoria. Revista Latinoamericana de Psicología, 41, 257-276.

[4] Anderson, P. (2008) Towards a Developmental Model of Executive Function. In: Anderson, V., Jacobs, R. and Anderson, P., Eds., Executive Functions and the Frontal Lobes: a Lifespan Perspective, Taylor \& Francis, New York, 3-22.

[5] Hale, S. (1990) A Global Developmental Trend in Cognitive Processing Speed. Child Development, 61, 653-663. http://dx.doi.org/10.2307/1130951

[6] Corsi, P. (1972) Memory and the Medial Temporal Region of the Brain. Doctoral Thesis in Philosophy, McGill University, Montreal.

[7] Orsini, A. (1994) Corsi’s Block Tapping Test: Standardization and Concurrent Validity with WISC-R for Children Aged 11 to 16. Perceptual and Motor Skills, 79, 1547-1554. http://dx.doi.org/10.2466/pms.1994.79.3f.1547

[8] Guevara-Pérez, M., Sanz-Martin, A., Hernández-González, M. and Sandoval-Carrillo, I. (2014) CubMemPC: Prueba computarizada para evaluar la memoria a corto plazo visoespacial con y sin distractores. Revista Mexicana de Ingeniería Biomédica, 35, 175-186.

[9] van Asselen, M., Kessels, R., Neggers, S., Kapelle, J., Frijns, C. and Postma, A. (2006) Brain Areas Involved in Spatial Working Memory. Neuropsychologia, 44, 1185-1194. http://dx.doi.org/10.1016/j.neuropsychologia.2005.10.005

[10] Kessels, R., van Zandvoort, M., Postma, A., Kappelle, J. and de Haan, E. (2000) The Corsi Block-Tapping Task: Standardization and Normative Data. Applied Neuropsychology, 7, 252-258. http://dx.doi.org/10.1207/S15324826AN0704 8

[11] Baddeley, A. (2000) The Episodic Buffer: A New Component of Working Memory? Trends in Cognitive Sciences, 4, 417-423. http://dx.doi.org/10.1016/S1364-6613(00)01538-2

[12] Smith, E., Jonides, J., Marshuetz, C. and Koeppe, R. (1998) Components of Verbal Working Memory: Evidence from Neuroimaging. Proceedings of the National Academy of Sciences of the United States of America, 95, 876-882. http://dx.doi.org/10.1073/pnas.95.3.876

[13] Courtney, S., Ungerleider, L., Keil, K. and Haxby, J. (1996) Object and Spatial Visual Working Memory Activate Separate Neural Systems in Human Cortex. Cerebral Cortex, 6, 39-49. http://dx.doi.org/10.1093/cercor/6.1.39

[14] Fuster, J. (2002) Frontal Lobe and Cognitive Development. Journal of Neurocytology, 31, 373-385. http://dx.doi.org/10.1023/A:1024190429920

[15] Walter, H., Bretschneider, V., Grön, G., Zurowski, B., Wunderlich, A., Tomczak, R. and Spitzer, M. (2003) Evidence for Quantitative Domain Dominance for Verbal and Spatial Working Memory in Frontal and Parietal Cortex. Cortex, 39, 897-911. http://dx.doi.org/10.1016/S0010-9452(08)70869-4

[16] Nelson, C., Monk, C., Lin, J., Carver, L., Thomas, K. and Truwit, C. (2000) Functional Neuroanatomy of Spatial Working Memory in Children. Developmental Psychology, 36, 109-116. http://dx.doi.org/10.1037/0012-1649.36.1.109

[17] Sarnthein, J., Petsche, H., Reppelsberger, P., Shaw, G.L. and von Stein, A. (1998) Synchronization between Prefrontal and Posterior Association Cortex during Human Working Memory. Proceedings of the National Academy of Sciences of the United States of America, 95, 7092-7096. http://dx.doi.org/10.1073/pnas.95.12.7092

[18] Thomason, M., Race, E., Burrows, B., Whitfield-Gabrieli, S., Glover, G. and Gabrieli, J. (2009) Development of Spatial and Verbal Working Memory Capacity in the Human Brain. Journal of Cognitive Neuroscience, 21, 316-332. http://dx.doi.org/10.1162/jocn.2008.21028

[19] Thatcher, R., North, D. and Biver, C. (2008) Development of Cortical Connections as Measure by EEG Coherence and Phase Delay. Human Brain Mapping, 29, 1400-1415. http://dx.doi.org/10.1002/hbm.20474 
[20] Horwitz, B. (2003) The Elusive Concept of Brain Connectivity. Neuroimage, 19, 466-470. http://dx.doi.org/10.1016/S1053-8119(03)00112-5

[21] Guevara, M., RizoMartínez, L., Robles Aguirre, F. and Hernández González, M. (2012) Prefrontal-Parietal Correlation during Performance of the Towers of Hanoi Task in Male Children, Adolescents and Young Adults. Developmental Cognitive Neuroscience, 2, 129-138. http://dx.doi.org/10.1016/j.dcn.2011.05.002

[22] Ruíz-Díaz, M., Hernández-González, M., Guevara, M.A., Amezcua, C. and Agmo, A. (2012) Prefrontal EEG Correlation during Tower of Hanoi and WCST Performance: Effect of Emotional Visual Stimuli. International Society for Sexual Medicine, 9, 2631-2640. http://dx.doi.org/10.1111/j.1743-6109.2012.02782.x

[23] Sanz-Martin, A., Hernández-González, M., Santana, G., Guevara, M.A., Gumá, E. and Amezcua, C. (2012) Effects of Alcohol on Performance of the Tower of London Task in Relation to the Menstrual Cycle: An Electroencephalographic Study. Behavioural Pharmacology, 23, 637-649. http://dx.doi.org/10.1097/FBP.0b013e3283584748

[24] Guevara-Pérez, M. and Corsi-Cabrera, M. (1996) EEG Coherence or EEG Correlation. International Journal of Psychophisiology, 23, 145-153. http://dx.doi.org/10.1016/S0167-8760(96)00038-4

[25] Sauseng, P., Klimesch, W., Schabus, M. and Doppelmayr, M. (2005) Fronto-Parietal EEG Coherence in Theta and Upper Alpha Reflect Central Executive Functions of Working Memory. International Journal of Psychophysiology, 57, 97-103. http://dx.doi.org/10.1016/j.ijpsycho.2005.03.018

[26] Kawasaki, M., Kitajo, K. and Yamaguchi, Y. (2010) Dynamic Links between Theta Executive Functions and Alpha Storage Buffers in Auditory and Visual Working Memory. European Journal of Neuroscience, 31, 1683-1689. http://dx.doi.org/10.1111/j.1460-9568.2010.07217.x

[27] Kwon, H., Reiss, A.L. and Menon, V. (2002) Neural Basis of Protracted Developmental Changes in Visuo-Spatial Working Memory. Proceedings of the National Academy of Sciences of the United States of America, 99, 1336-1341. http://dx.doi.org/10.1073/pnas.162486399

[28] De Luca, C. and Leventer, R. (2008) Developmental Trajectories of Executive Functions across the Lifespan. In: Anderson, V., Jacobs, R. and Anderson, P., Eds., Executive Functions and the Frontal Lobes: A Lifespan Perspective, Taylor \& Francis Group, New York, 23-56.

[29] Wechsler, D. (2003) Escala de Inteligencia Wechsler para Niños (WISC-IV). Psychological Corporation, San Antonio.

[30] Wechsler, D. (1997) Escala de Inteligencia para Adultos, WAIS-Español. El Manual Moderno, Mexico, D.F.

[31] Ostrosky-Solis, F., Gómez, M., Matute, E., Roselli, M., Ardila, A. and Pineda, D. (1997) Neuropsi Atención y Memoria. Manual Moderno, México, D.F.

[32] Jasper, H.A. (1958) The Ten-Twenty System of the International Federation of Electroencephalography. Clinical Neurophysiology, 10, 371-375.

[33] Harmony, T., Alba, A., Marroquín, J. and González-Frankenberger, B. (2009) Time-Frequency-Topographic Analysis of Induced Power and Synchrony of EEG Signals during a Go/No-Go Task. International Journal of Psychophysiology, 71, 9-16. http://dx.doi.org/10.1016/j.ijpsycho.2008.07.020

[34] Herwig, U., Satrapi, P. and Schönfeldt-Lecuona, C. (2003) Using the International 10-20 EEG System for Positioning of Transcranial Magnetic Stimulation. Brain Topography, 16, 95-99. http://dx.doi.org/10.1023/B:BRAT.0000006333.93597.9d

[35] Guevara, M., Ramos, J., Hernández-González, M., Madera-Carrillo, H. and Corsi-Cabrera, M. (2000) CAPTUSEN: Un sistema para la adquisición computarizada del EEG y los Potenciales Relacionados a Eventos. Revista Mexicana de Psicología, 17, 77-88.

[36] Guevara, M.A., Sanz-Martin, A., Corsi-Cabrera, M., Amezcua-Gutierrez, C. and Hernández-González, M. (2010) CHECASEN: Programa para revisar señales EEG fuera de línea. Revista Mexicana de IngenieríaBiomédica, 31, 135141.

[37] Guevara, M.A. and Hernández-González, M. (2009) EEGmagic: Programa para analizar señales electroencefalográficas. Revista Mexicana de Ingeniería Biomédica, 30, 41-53.

[38] Sanz-Martin, A., Hernández-González, M., Guevara, M.A., Santanta, G. and Gumá-Díaz, E. (2014) Efecto del alcohol en la organización eléctrica cerebral durante una tarea de memoria de trabajo visuoespacial y su relación con el ciclo menstrual. Revista de Neurología, 58, 103-112.

[39] Orsini, A., Chiacchio, I., Cinque, M., Cocchiaro, C., Schiappa, O. and Grossi, D. (1986) Effects of Age, Education and Sex on Two Test of Immediate Memory: A Study of Normal Subjects from 20 to 99 Years Old. Perceptual and Motor Skills, 63, 727-732. http://dx.doi.org/10.2466/pms.1986.63.2.727

[40] Antunes, R., Zachi, E., Roque, D., Taub, A. and Fix, D. (2011) Memory Span Measured by the Spatial Span Tests of the Cambridge Neuropsychological Test Automated Battery in a Group of Brazilian Children and Adolescents. Dementia Neuropsychologia, 5, 129-134. 
[41] Merriam-Webster (1986) Webster's Third New International Dictionary of the English Language. Merriam-Webster, Springfield.

[42] Chuah, L. and Maybery, M. (1999) Verbal and Spatial Short-Term Memory: Common Sources of Developmental Change? Journal of Experimental Child Psychology, 73, 7-44. http://dx.doi.org/10.1006/jecp.1999.2493

[43] Salthouse, T. (1992) Influence of Processing Speed on Adult Age Differences in Working Memory. Acta Psycholgica, 79, 155-170. http://dx.doi.org/10.1016/0001-6918(92)90030-H

[44] Curtis, C., Zald, D. and Pardo, J. (2000) Organization of Working Memory within the Human Prefrontal Cortex: A PET Study of Self-Ordered Object Working Memory. Neuropsychologia, 38, 1503-1510. http://dx.doi.org/10.1016/S0028-3932(00)00062-2

[45] Rypma, B., Prabhakaran, V., Desmond, J., Glover, G. and Gabrieli, J. (1999) Load-Dependent Roles of Frontal Brain Regions in the Maintenance of Working Memory. Neuroimage, 9, 216-226. http://dx.doi.org/10.1006/nimg.1998.0404

[46] Tsujimoto, S., Yamamoto, T., Kawaguchi, H., Koizumi, H. and Sawaguchi, T. (2004) Prefrontal Cortical Activation Associated with Working Memory in Young Adults and Preschool Children: An Event-Related Optical Topography Study. Cerebral Cortex, 14, 703-712. http://dx.doi.org/10.1093/cercor/bhh030

[47] Baker, S.C., Rogers, R.D., Owen, A.M., Frith, C.D., Dolan, R.J., Frackowiak, R.S.J. and Robbins, T.W. (1996) Neural Systems Engaged by Planning: A PET Study of the Tower of London Task. Neuropsychologia, 34, 515-526. http://dx.doi.org/10.1016/0028-3932(95)00133-6

[48] Braver, T., Cohen, J., Nystrom, L., Jonides, J., Smith, E. and Noll, D. (1997) A Parametric Study of Prefrontal Cortex Involvement in Human Working Memory. Neuroimage, 5, 49-62. http://dx.doi.org/10.1006/nimg.1996.0247

[49] Klimesch, W., Doppelmayr, M., Schwaiger, J., Auinger, P. and Winkler, T. (1999) "Paradoxical” Alpha Synchronization in a Memory Task. Cognitive Brain Research, 7, 493-501. http://dx.doi.org/10.1016/S0926-6410(98)00056-1

[50] Tallon-Baudry, C., Kreiter, A. and Bertrand, O. (1999) Sustained and Transient Oscillatory Responses in the Gamma and Beta Bands in a Visual Short-Term Memory Task in Humans. Visual Neuroscience, 16, 449-459. http://dx.doi.org/10.1017/S0952523899163065

[51] Kessels, R., van der Berg, E., Ruis, C. and Brands, A. (2008) The Backward Span of the Corsi Block-Tapping Task and Its Association with the WAIS-III Digit Span. Assessment, 15, 426-434. http://dx.doi.org/10.1177/1073191108315611

[52] Klingberg, T., Forssberg, H. and Wersterberg, H. (2002) Increased Brain Activity in Frontal and Parietal Cortex Underlies the Development of Visuospatial Working Memory Capacity during Childhood. Journal of Cognitive Neuroscience, 14, 1-10. http://dx.doi.org/10.1162/089892902317205276

[53] Scherf, S., Sweeney, J. and Luna, B. (2006) Brain Basis of Developmental Change in VWM. Journal of Cognitive Neuroscience, 18, 1045-1058. http://dx.doi.org/10.1162/jocn.2006.18.7.1045

[54] Luna, B., Thulborn, K., Munoz, D., Merriam, E., Garver, K., Minshew, N., Keshavan, C.R., Genovese, W.F.E. and Sweeney, J.A. (2001) Maturation of Widely Distributed Brain Function Subserves Cognitive Development. Neuroimage, 13, 786-793. http://dx.doi.org/10.1006/nimg.2000.0743

[55] Libertus, M., Branon, E. and Pelphrey, K. (2009) Developmental Changes in Category-Specific Brain Responses to Numbers and Letters in a Working Memory Task. Neuroimage, 44, 1404-1414. http://dx.doi.org/10.1016/j.neuroimage.2008.10.027

[56] Sowell, E., Thompson, P., Tessner, K. and Toga, A. (2001) Mapping Continued Brain Growth and Gray Matter Density Reduction in Dorsal Frontal Cortex: Inverse Relationships during Post-Adolescent Brain Maturation. The Journal of Neuroscience, 21, 8819-8829.

[57] Olesen, P., Nagy, Z., Westerberg, H. and Klingberg, T. (2003) Combined Analysis of DTI and fMRI Data Reveals a Joint Maturation of White and Grey Matter in a Fronto-Parietal Network. Cognitive Brain Research, 18, 48-57. http://dx.doi.org/10.1016/j.cogbrainres.2003.09.003

[58] Baddeley, A. (1998) Recent Developments in Working Memory. Current Opinion in Neurobiology, 8, $234-238$. http://dx.doi.org/10.1016/S0959-4388(98)80145-1

[59] Weiss, S., Mueller, H., Schack, B., King, J., Kutas, M. and Rappelsberger, P. (2005) Increased Neuronal Communication Accompanying Sentence Comprehension. International Journal of Psychophysiology, 57, 129-141. http://dx.doi.org/10.1016/j.ijpsycho.2005.03.013

[60] Roopun, A., Cunningham, M., Racca, C., Alter, K., Traub, R. and Whittington, M. (2008) Region-Specific Changes in Gamma and Beta2 Rhythms in NMDA Receptor Dysfunction Models of Schizophrenia. Schizophrenia Bulletin, 34, 962-973. http://dx.doi.org/10.1093/schbul/sbn059

[61] Gevins, A., Smith, M., McEvoy, L. and Yu, D. (1997) High-Resolution EEG Mapping of Cortical Activation Related to Working Memory: Effects of Task Difficulty, Type of Processing, and Practice. Cerebral Cortex, 7, 374-385. http://dx.doi.org/10.1093/cercor/7.4.374 